\title{
A new bracing system for improvement of seismic performance of steel jacket type offshore platforms with float-over-deck
}

\author{
Behrouz Asgarian and Hamed Rahman Shokrgozar* \\ Department of Civil Engineering, K. N. Toosi University of Technology, No. 1346, Valiasr Street, Mirdamad Intersection \\ 19967, P.O. Box. 15875-4416, Tehran, Iran
}

(C) China University of Petroleum (Beijing) and Springer-Verlag Berlin Heidelberg 2013

\begin{abstract}
In this paper, the seismic response of a newly designed steel jacket offshore platform with a float over deck (FOD) system in the Persian Gulf was investigated through incremental dynamic analysis. Comparison of incremental dynamic analysis results for both directions of the platform shows that the lateral strength of the platform in the float over direction is less than its lateral strength in other direction. Dynamic characteristics measurement of a scale model of platform was also performed using forced vibration tests. From experimental measurement of the scaled model, it was observed that dynamic characteristic of the platform is different in the float over direction compared to the other direction. Therefore, a new offshore installed bracing system for the float over direction was proposed for improvement of seismic performance of this type of platform. Finally, the structure with the modified system was assessed using the probabilistic seismic assessment method as well as experimental measurement of its dynamic characteristics. It was observed that the proposed offshore installed bracing system improves the performance of platforms subjected to strong ground motion.
\end{abstract}

Key words: Steel jacket type offshore platform, float-over deck, mean annual frequency, force vibration test, seismic performance, dynamic characteristics

\section{Introduction}

Jacket type offshore platforms are comprised of three main parts structurally, the jacket, pile foundation and deck. There are two main methods for the installation of the offshore deck on jacket namely lifting method and float over deck (FOD) installation method. The float over method is used usually for installation of heavier decks in which the deck is placed on a float over barge and then it is installed on a pre-installed jacket by barge ballasting. The sequence of the float over deck installation is described by O'Neill et al (2000). In the jacket type offshore platform with the float-over deck installation, there is not any vertical bracing in the top bay of the installed jacket in the FOD direction in order to allow the float over barge to come within the jacket legs. In the other direction, there is not any restriction for configuration of the jacket vertical bracing in all bays.

Jacket type offshore platforms during their service life are subjected to various lateral dynamic loads such as earthquake, wave forces, wind forces and ship impact. Dynamic response of the structures is highly dependent on the characteristics

*Corresponding author. email: h_rshokrgozar@yahoo.com Received May 20, 2012 of the structures. For this type of offshore platform, the dynamic behavior of the structure in two main directions is totally different. In one of the direction, due to absence of vertical bracing in the top bay of the jacket (because of FOD installation), the system is more flexible and vertical irregularity exists. On the other hand, in the other direction, the system is stiffer and generally more regular in the vertical direction. Lateral strength of such a braced frame is also affected by the vertical bracing configuration. Consequently, the lateral strength in the float over direction is generally less than the strength in the other direction.

In this paper, dynamic behavior of a newly installed jacket type offshore platform with the FOD installation system in the Persian Gulf was studied by numerical and experimental investigation. The probabilistic seismic assessment of the platform was performed first for both directions. Then by experimental observation of the response of the scaled model of the platform, the dynamic characteristics of the platform for both directions were evaluated. An offshoreinstalled vertical bracing was proposed for the float over deck installation direction to strengthen the platform against lateral loads. The effectiveness of the proposed method was also validated by numerical seismic assessment of the real structure and experimental study of the strengthened scaled platform. 


\section{Probabilistic seismic assessment of an off- shore platform with a FOD system}

In order to evaluate the seismic performance of structures, the SAC-FEMA (FEMA 2000a; 2000b; 2000c) developed a closed form probabilistic assessment method. In this method which is a PEER probabilistic framework, performance objective of the structures is stated in terms of mean annual frequency (MAF) of exceeding a performance level. Jalayer and Cornell (2003) presented a closed-form analytical solution for mean annual frequency of exceedance by taking into account both the aleatory and epistemic uncertainties. The mean annual frequency of exceeding a specified limit state $H_{\mathrm{LS}}$, is defined as follows:

$$
H_{\mathrm{LS}}=v \cdot P[D \geq C]=\int v \cdot P[D \geq c] f_{c}(c) \mathrm{d} c
$$

where $P[D \geq C]$ is the probability of the exceedance of demand $(D)$ rather capacity $(C) ; v$ is the rate parameter; and $f_{c}(c)$ is the probability density function.

$H_{\text {LS }}$ can be determined by decomposing the above equation into tractable pieces, the seismological part and structural engineering part, and using the total probability theorem (TPT) (Jalayer and Cornell, 2003).

The above equation can be solved by separating it into three elements, demand, capacity variable, and spectral acceleration hazard. The closed-form analytical expression of $H_{\mathrm{LS}}$ after solving above equation is as follows:

$$
H_{\mathrm{LS}}=k_{0}\left(S_{a}^{\eta_{C}}\right)^{-k} \mathrm{e}^{\frac{1}{2} \beta_{\mathrm{UH}}^{2}} \mathrm{e}^{\frac{1}{2} \frac{k}{2}^{2}\left(\beta_{\mathrm{RD}}^{2}+\beta_{\mathrm{UD}}^{2}\right)} \mathrm{e}^{\frac{1}{2} \frac{k}{2}^{2}\left(\beta_{\mathrm{RC}}^{2}+\beta_{\mathrm{UC}}^{2}\right)}
$$

where $a$ and $b$ are parameters of the power-law model that expresses the relationship between spectral acceleration (IM) and (median) interstory drift (DM), $\eta_{D}(x)=a S_{a}^{b} ; \beta_{\mathrm{UD}}$, $\beta_{\mathrm{RD}}, \beta_{\mathrm{UC}}$, and $\beta_{\mathrm{RC}}$ are uncertainty and randomness in drift demand and capacity evaluation; $k_{0}$ and $k$ are parameters that define the spectral acceleration hazard curve by a power-law relationship $\left(H_{S_{a}}\left(S_{a}\right)=P\left[S_{a} \geq x\right]=k_{0} x^{-k}\right)$ and $\beta_{\mathrm{UH}}$ is the uncertainty in the spectral acceleration hazard (Jalayer and Cornell, 2003).

\subsection{Platform description}

The mean annual frequency of exceeding a specified limit state of a newly designed jacket type offshore platform with a float over deck installation system in Persian Gulf was evaluated. For this purpose, the full 3D-model of the jacket, deck, pile foundation and its interaction with surrounding soil was developed. The height of the structure (jacket and deck) is about $102 \mathrm{~m}$ and the water depth is about $72 \mathrm{~m}$. The jacket plan and the vertical elevation of structure are shown in Fig. 1. Eight skirt piles are embedded in the corners of the jacket. The total weight of the jacket and deck is about 8,680 tonnes. The platform has five-story deck and four-story jacket. To install the heavy deck using the float over method, there cannot be any vertical bracing element at sea level (top bay of the jacket) of Rows A \& C. Due to absence of the vertical bracing; the portal action is governed by a nonlinear range of deformation in this direction. The main characteristics of the offshore platform are listed in Table 1.

Table 1 Main characteristics of the platform

\begin{tabular}{cc}
\hline Parameter & Value \\
\hline Water depth, $\mathrm{m}$ & 72 \\
Platform height, $\mathrm{m}$ & 10 \\
Jacket dimensions (horizontal \\
plan), $\mathrm{m}(x$-dir. $) \times \mathrm{m}(y$-dir.) & $31 \times 34$ \\
Total number of jacket legs & 6 \\
Total number of jacket piles & 8 \\
Jacket piles & Skirt piles \\
Pile diameter (in) and thickness (in) & $72 \times 1.5$ \\
Pile penetration, $\mathrm{m}$ & 62 \\
\hline
\end{tabular}

\subsubsection{Modeling of the platform}

A numerical model of the platform was developed using Opensees software (Mazzoni et al, 2006). All members were modeled using beam-column elements. The fiber section was considered for the modeling of the cross section of all elements, and P-delta stiffness matrix stiffness was used for the geometric nonlinearity that is accurate enough for such an application. The mass used in the dynamic analysis consisted of the mass of the platform associated with gravity loading, the mass of the entrapped fluids in main legs, and the hydrodynamic added mass. The added mass was estimated as the mass of the displaced water for motion transverse to the longitudinal axis of the individual structural members. In computing the dynamic response of the platform, a viscous damping ratio of $2 \%$ was used for the analysis. The pile, soil and the soil-pile-structure interaction effect were also modeled using a beam on nonlinear winkler foundation (BNWF) model.

The beam on nonlinear winkler foundation model for modeling piles should allow for the variation of soil properties through depth, nonlinear soil behavior, nonlinear behavior of pile-soil interfaces and energy dissipation through radiation and hysteretic damping. Special attention needs to be given to the evaluation of the free-field excitation. The computed ground motion at different levels if the soil was applied to the nodal boundary supports represents the support motions (Kimiaei et al, 2004).

The general view of a BNWF model and its main components in dynamic nonlinear response analysis of pile was described by Boulanger et al (1999).

\subsubsection{Free field excitations}

Time histories of the free field ground motion are usually computed using common site response analysis techniques. In this paper, the ground motion of the soil layer was calculated due to earthquake excitations applied at bedrock. The results of such free field analysis (acceleration or displacement time history at different soil layers) were then used as the input excitation at support nodes of the BNWF-fiber element model.

In the present study, the nonlinear stress-strain response of soil layers was approximated by a nonlinear approach. In 


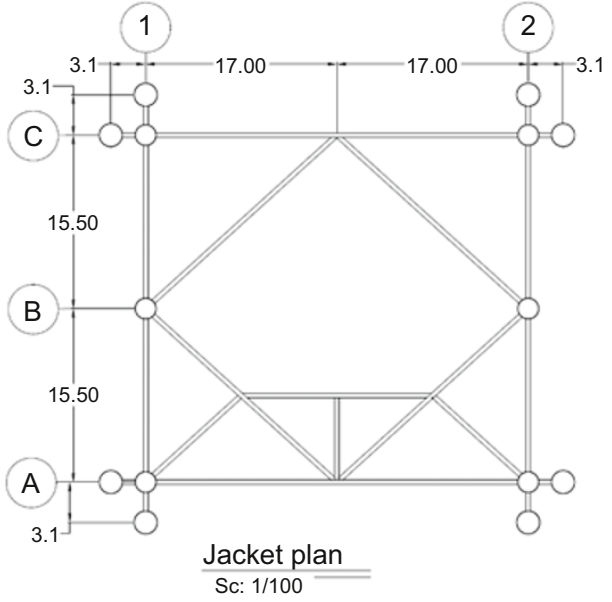

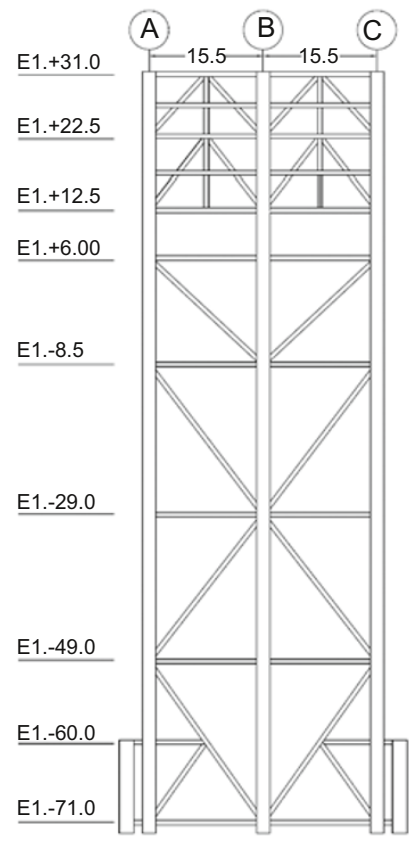

Rows 1 \& 2

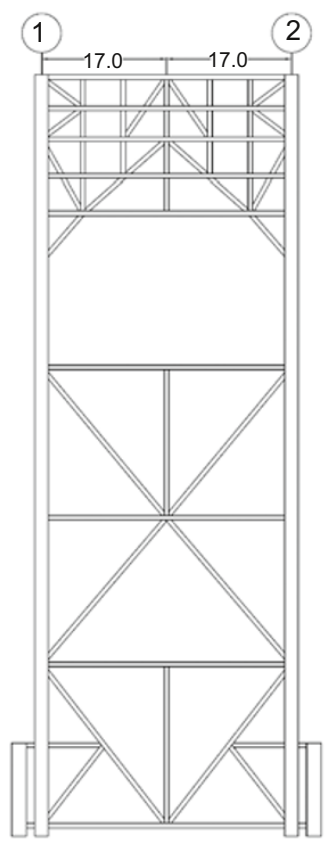

Rows A \& C Sc: $1 / 100$

Fig. 1 Elevation of the steel jacket platform

the analyses, the model proposed by Iwan (1976) and Mórz (1967) was used in which the nonlinear and hysteretic stressstrain behavior of soil was approximated by tangential shear modulus. A computer program NERA (nonlinear earthquake site response analysis) developed by Bardet and Tobita (2001) was used for free field ground motion analysis. The low strain shear modulus $G_{\max }$ was calculated from the equations derived by Seed and Idriss (1970):

$$
\frac{G_{\max }}{P_{\mathrm{atm}}}=21.8 K_{2, \max } \sqrt{\frac{\sigma_{\mathrm{m}}^{\prime}}{P_{\mathrm{atm}}}} \quad \text { for } s \text { and }
$$

with

$$
\begin{aligned}
& K_{2, \max }=65 \\
& \sigma_{\mathrm{m}}^{\prime}=\left(1+2 K_{0}\right) \sigma_{\mathrm{vc}}^{\prime} / 3 \\
& K_{0}=0.6
\end{aligned}
$$

$$
\frac{G_{\max }}{c_{\mathrm{u}}}=380 \text { for clay }
$$

where $P_{\mathrm{atm}}$ is the atmospheric pressure; $c_{\mathrm{u}}$ is the undrained shear strength.

\subsubsection{Pile and soil modeling}

Piles and surrounding soil were subdivided into a number of discrete layers. Pile response was traced independently at nodal points of the pile segments within each layer. The dynamic characteristics of the pile segments (i.e. stiffness, damping and mass) were established at these nodes. The soil reaction to pile movement during transient seismic loading comprises stiffness and damping components. In the present study, the soil stiffness was established using $p-y$ (lateral soil resistance versus lateral soil deflection) as well as $t-z$ and $Q-z$ spring elements. The soil stiffness was modeled, employing $p-y, t-z$ and $Q-z$ curves recommended by API. Furthermore, the damping component of the soil resistance was represented by a dashpot whose coefficient was established based on the model proposed by Berger et al (1977), i.e.

$$
C_{\mathrm{L}}=4 B \rho v_{\mathrm{s}}
$$

where $B$ is the pile diameter; $v_{\mathrm{s}}$ is the soil shear wave velocity; and $\rho$ is the soil unit density.

\subsubsection{Record selection}

Previous studies (Shome and Cornell, 1999) have shown that for mid-rise buildings, ten to twenty records are usually enough to provide sufficient accuracy in the estimation of seismic demands. Consequently, a set of sixteen ground motion records was selected that belong to a bin of relatively large magnitudes of 6 to 7 and moderate distances (Table 2).

\subsection{Incremental dynamic analysis of the platform}

Incremental dynamic analysis (IDA) was performed at increasing levels of intensity measure (IM) by increasing steps for both directions. Fig. 2 shows a 3D model of the platform.

Figs. 3 and 4 show all sixteen IDA curves in the Rows A $\& \mathrm{C}$ and Rows $1 \& 2$ in which first-mode spectral acceleration $S_{a}\left(T_{1}, 5 \%\right)$ is considered as IM and maximum interstory drift ratio is considered as DM.

\subsection{Defining limit-states}

In order to do probabilistic seismic assessment, it is required to define limit-states. In this study, two limit states were used: immediate occupancy (IO) and collapse prevention (CP). It is assumed to set the IO limit-state to appear at $\theta_{\max }=$ $1 \%$ or elastic limit state whichever occurs first or for ground motions with a $50 \%$ chance of exceedance in 50 years and the CP limit-state was not exceeded on the IDA curve until the final point where the local tangent reaches $20 \%$ of the elastic slope or a drift ratio of $\theta_{\max }=10 \%$, whichever occurs first in IM terms. The main idea is to place the CP limit-state at a point where the IDA curve is softening towards the flat line but at low enough values of $\theta_{\max }$ (less than $10 \%$, for ground motions with a $2 \%$ chance of exceedance in 50 years). 
Table 2 Ground motion earthquake records used in this study

\begin{tabular}{|c|c|c|c|c|c|c|}
\hline Event, Year, $M^{*}{ }_{W}$ & ID & Station & $\phi^{\circ \dagger}$ & Soil ${ }^{ \pm}$ & $R^{\hbar}$ & PGA \\
\hline \multirow{6}{*}{ Loma Prieta, 1989-06-09 } & R1 & Agnews State Hospital & 090 & $\mathrm{C}, \mathrm{D}$ & 28.2 & 0.159 \\
\hline & $\mathrm{R} 2$ & Hollister Diff. Array & 255 &,$- \mathrm{D}$ & 25.8 & 0.279 \\
\hline & $\mathrm{R} 3$ & Anderson Dam Downstrm & 270 & $\mathrm{~B}, \mathrm{D}$ & 21.4 & 0.244 \\
\hline & $\mathrm{R} 4$ & Coyote Lake Dam Downstrm & 289 & $\mathrm{~B}, \mathrm{D}$ & 22.3 & 0.179 \\
\hline & R5 & Sunnyvale Colton Ave & 270 & $\mathrm{C}, \mathrm{D}$ & 28.8 & 0.207 \\
\hline & R6 & Anderson Dam Downstrm & 360 & $\mathrm{~B}, \mathrm{D}$ & 21.4 & 0.24 \\
\hline \multirow{2}{*}{ Northridge, 1994-06-07 } & R7 & LA, Baldwin Hills & 090 & $\mathrm{~B}, \mathrm{~B}$ & 31.3 & 0.239 \\
\hline & $\mathrm{R} 8$ & LA, Hollywood Storage FF & 360 & $\mathrm{C}, \mathrm{D}$ & 25.5 & 0.358 \\
\hline \multirow{5}{*}{ Imperial Valley, 1979-06-05 } & R9 & Computertas & 285 & $\mathrm{C}, \mathrm{D}$ & 32.6 & 0.147 \\
\hline & R10 & El Centro Array \# 12 & 140 & $\mathrm{C}, \mathrm{D}$ & 18.2 & 0.143 \\
\hline & R11 & Chihuahua & 012 & $\mathrm{C}, \mathrm{D}$ & 28.7 & 0.27 \\
\hline & R12 & El Centro Array \# 13 & 230 & $\mathrm{C}, \mathrm{D}$ & 21.9 & 0.139 \\
\hline & R13 & Computertas & 015 & $\mathrm{C}, \mathrm{D}$ & 32.6 & 0.186 \\
\hline \multirow{2}{*}{ San Fernando, 1971-06-06 } & R14 & LA, Hollywood Stor. Lot & 180 & $\mathrm{C}, \mathrm{D}$ & 21.2 & 0.174 \\
\hline & R15 & LA, Hollywood Stor. Lot & 090 & $\mathrm{C}, \mathrm{D}$ & 21.2 & 0.21 \\
\hline Superstition Hills, 1987-06-07 & R16 & Wildlife Liquefaction Array & 360 & $\mathrm{C}, \mathrm{D}$ & 24.4 & 0.2 \\
\hline
\end{tabular}

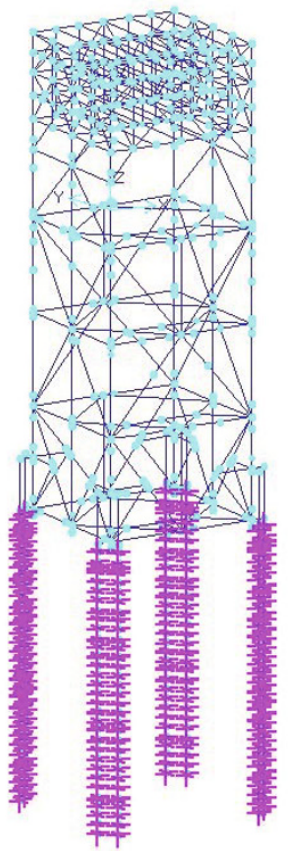

Fig. 2 3D model of steel jacket type offshore platform in Opensees

\subsection{Evaluation of the mean annual frequency (MAF)}

In this section, all parameters that are essential in the probabilistic seismic assessment of the structure were obtained from the result of incremental dynamic analysis. For this purpose, it was necessary to summarize IDA curves. They could be easily summarized into some central value

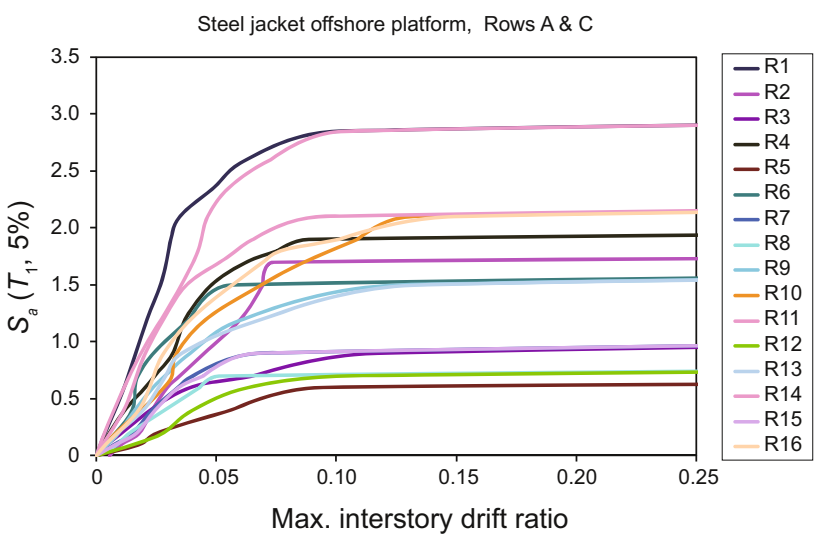

Fig. 3 IDA curves (for $T_{1}=2.9 \mathrm{sec}$ ), steel jacket offshore platform in Rows A \& C, with maximum interstory drift ratio

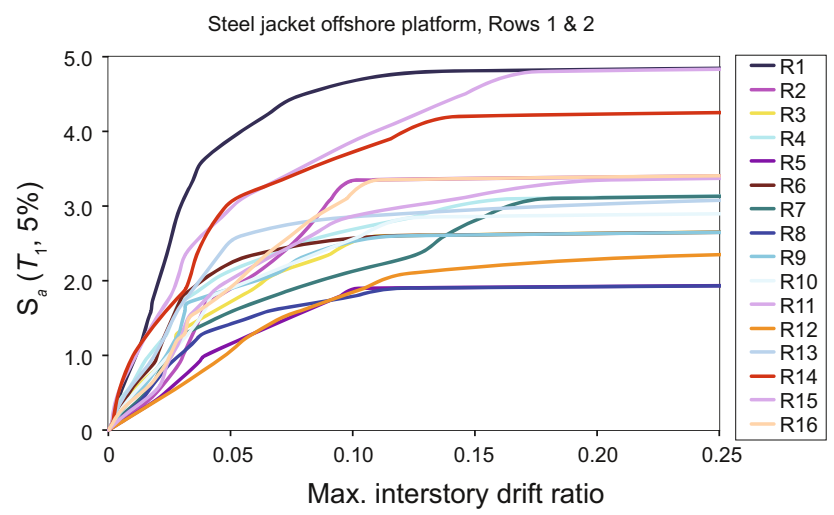

Fig. 4 IDA curves (for $T_{1}=2.67 \mathrm{sec}$ ), steel jacket offshore platform in Rows $1 \& 2$, with maximum interstory drift ratio 
(the mean or the median) and a measure of dispersion (the standard deviation, or the difference between two fractiles). Consequently, the $16 \%, 50 \%$ and $84 \%$ fractile values of DM and IM capacity were chosen. Fig. 5 shows the summarized IDA curve in the Rows A \& $\mathrm{C}$ and Rows $1 \& 2$.

Based on the Iranian earthquake code (Standard No. 2800, 2005), the site-specific hazard curve was selected for a site located in the Persian Gulf at $T=2.8 \mathrm{sec}$ in which $T$ is first natural period of the structure. By using the power-law relationship, which was introduced in the previous section, the line with slope $k$ and intercept $k_{0}$ was fitted to the hazard curve around the region of interest (e.g., MAFs between 1/72 or $50 \%$ frequency of exceedance in 50 years, and $1 / 2475$ or $2 \%$ frequency of exceedance). Here, $k, k_{0}$ and $\beta_{\mathrm{UH}}$ (uncertainty in the spectral hazard acceleration) are 2.73, 0.000196 and 0.65 , respectively. The fitted curves to median IDA curves in Fig. 5 (curve $50 \%$ in the Rows A \& C and Rows $1 \& 2$ ) were calculated as power-law equations. These equations were obtained as follows and are shown in Fig. 6.

$$
\begin{aligned}
& \eta_{D}(x)=a x_{a}^{b}=0.051 x_{a}^{1.47}, \quad r=0.987 \quad x \text { dir. } \\
& \eta_{D}(x)=a x_{a}^{b}=0.051 x_{a}^{1.59}, r=0.981 \quad y \text { dir. }
\end{aligned}
$$

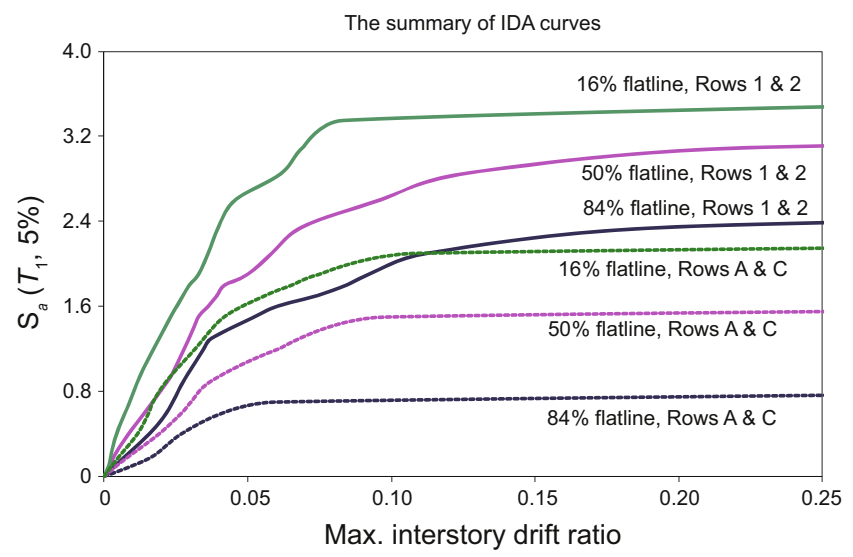

Fig. 5 The summery of IDA curves in the Rows A \& C and Rows $1 \& 2$ of the jacket platform

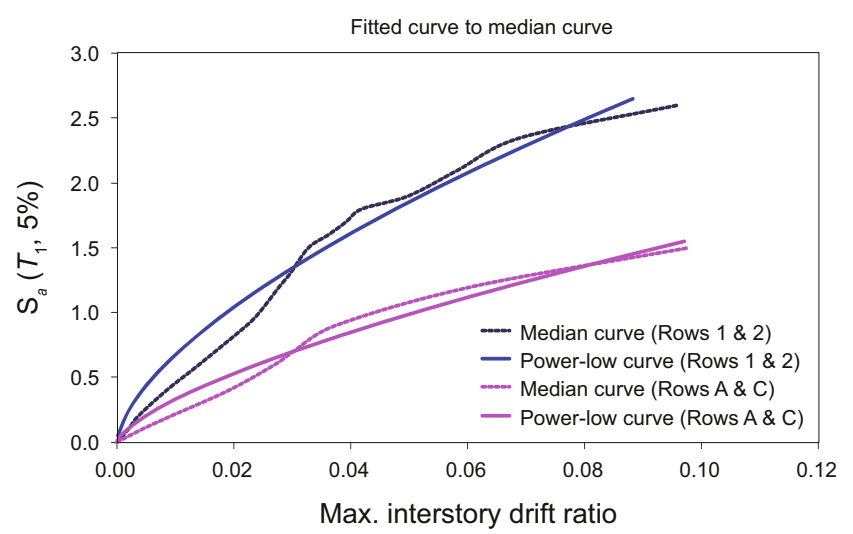

Fig. 6 Power-low relation fitted to median curve in Rows A \& C and Rows 1 \& 2
The limit state capacities, $C$, the fractional standard deviation of demand and capacity, $\beta_{\mathrm{RD}}$ and $\beta_{\mathrm{RC}}$ at each direction were estimated from the result of incremental dynamic analysis and are shown in Table 3. There are several practical ways to estimate the fractional standard deviation. In this paper, the fractional standard deviation of demand, $\beta_{\mathrm{RD}}$, was obtained by conducting a regression analysis of $\ln D$ and $\ln S_{a}$ for $16 \%, 50 \%$ and $84 \%$ fractile values. The fractional standard deviation of capacity, $\beta_{\mathrm{RC}}$, was estimated here by the average $\ln \left(S_{a}^{84^{\text {th }}} / S_{a}^{50^{\text {th }}}\right)$ and $\ln \left(S_{a}^{50^{\text {th }}} / S_{a}^{16^{\text {th }}}\right)$, where the symbols $S_{a}^{84^{\text {th }}}, S_{a}^{50^{\text {th }}}$, and $S_{a}^{16^{\text {th }}}$ denote the spectral acceleration values corresponding to $84 \%, 50 \%$ and $16 \%$ percentiles of the ordered data, respectively (Jalayer and Cornell, 2009). The modeling errors and other approximations involved in current analysis procedure was limited to the statistical uncertainty in the median due to the finite sample size $\left(n_{\text {sample }}=16\right)$ of ground motions. So $\beta_{\mathrm{UD}}$ and $\beta_{\mathrm{UC}}$ can be calculated as:

$$
\beta_{\mathrm{UD}}=\frac{\beta_{\mathrm{RD}}}{\sqrt{n_{\text {sample }}}}, \quad \beta_{\mathrm{UC}}=\frac{\beta_{\mathrm{RC}}}{\sqrt{n_{\text {sample }}}}
$$

The spectral acceleration corresponding to given capacity, $S_{a}^{\eta_{c}}$ in Eq. (1) can be found both analytically and graphically. The graphically estimation was used in this paper to increase the accuracy of the MAF estimation. The mean annual exceeded frequencies from each limit state were calculated from Eq. (1) which is shown in Table 4.

The probabilistic seismic assessment of the steel jacket type offshore platform with the FOD system reveals that the structure in Rows $1 \& 2$ has an acceptable mean annual frequency of exceeding the above mentioned limit states (immediate occupancy and collapse prevention). However, the MAF of exceeding the limit states in Rows A \& C (float over direction) do not satisfy recommended performance levels, and are less than the specified value 0.0139 and 0.0004 per annum. It can be seen that lack of the vertical bracing in the top bay of the jacket in Rows A \& C caused a major reduction in corresponding return period of the limit state compared to Rows 1 \& 2 in which the vertical bracing exists in all bays of the jacket. Meanwhile, it can be seen from IDA analysis results that the lateral strength in the float over direction (Rows A \& C) is less than the other direction (Rows 1 \& 2). Hence, it seems that modification of the vertical bracing configuration after deck installation can satisfy performance level and increase the lateral strength of the platform in the float over direction.

\subsection{Identification of the dynamic characteristic of the scaled model of the platform}

Experimental techniques have been widely applied to detect dynamic behaviour of systems. Performing test using dynamic measurement offers the opportunity to obtain information about the whole system based on a small number of measurements. These tests are based on determining the system vibration response and relating it to the modal properties. Two very common methods of the structural modal testing are the forced vibration and ambient vibration 
Table 3 Summarized capacities, randomness and uncertainty in parameters at each limit-state and each direction

\begin{tabular}{|c|c|c|c|c|c|c|c|c|c|c|c|c|c|}
\hline & \multicolumn{5}{|c|}{ Capacity parameters } & \multicolumn{4}{|c|}{ Randomness } & \multicolumn{4}{|c|}{ Uncertainty } \\
\hline & \multirow{2}{*}{ Percentile } & \multicolumn{2}{|c|}{$\theta_{\max }$} & \multicolumn{2}{|c|}{$S_{a}\left(T_{1}, 5 \%\right)$} & \multicolumn{2}{|c|}{$\beta_{\mathrm{RD}}$} & \multicolumn{2}{|c|}{$\beta_{\mathrm{RC}}$} & \multicolumn{2}{|c|}{$\beta_{\mathrm{UD}}$} & \multicolumn{2}{|c|}{$\beta_{\mathrm{UC}}$} \\
\hline & & IO & $\mathrm{CP}$ & IO & $\mathrm{CP}$ & IO & $\mathrm{CP}$ & IO & $\mathrm{CP}$ & IO & $\mathrm{CP}$ & IO & $\mathrm{CP}$ \\
\hline \multirow{3}{*}{ Rows A \& C } & 16 & 0.01 & 0.055 & 0.12 & 0.7 & & & & & & & & \\
\hline & 50 & 0.01 & 0.075 & 0.22 & 1.35 & 0.42 & 0.44 & 0.52 & 0.65 & 0.105 & 0.11 & 0.13 & 0.163 \\
\hline & 84 & 0.01 & 0.097 & 0.34 & 2.1 & & & & & & & & \\
\hline \multirow{3}{*}{ Rows $1 \& 2$} & 16 & 0.01 & 0.089 & 0.25 & 1.97 & & & & & & & & \\
\hline & 50 & 0.01 & 0.10 & 0.42 & 2.58 & 0.40 & 0.36 & 0.58 & 0.30 & 0.10 & 0.09 & 0.145 & 0.075 \\
\hline & 84 & 0.01 & 0.10 & 0.80 & 3.57 & & & & & & & & \\
\hline
\end{tabular}

Table 4 MAFs of exceedance and corresponding return periods

\begin{tabular}{ccccccc}
\hline & \multicolumn{2}{c}{ Rows A \& C } & & \multicolumn{2}{c}{ Rows 1 \& 2} \\
\cline { 2 - 3 } \cline { 5 - 6 } & IO & CP & & IO & CP \\
\hline$H_{\text {LS }}$ (MAF of exceedance) & 0.0343 & 0.00042 & & 0.00643 & 0.000025 \\
Return period, Years & 29 & 2380 & & 155 & 39726 \\
\hline
\end{tabular}

methods (Salawu and Williams, 1995). In case of the forced vibration test, the input excitation to the structure is provided by properly designed excitation systems, which entails application of a known force at particular frequencies or frequency bands of interest (Causevic, 1987; De Sortis et al, 2005). This method is based on the fact that if the loading on the structure and resulting responses are known, then the structural characteristics can be more unambiguously determined. These types of tests also have the advantage of the achieving larger signal to noise ratios in the response measurements (Salawu and Williams, 1995). In this paper, the forced vibration test was applied to the scaled model of the platform to measure its dynamic characteristics.

\subsubsection{Description of the scaled model platform}

The second step of this work is performing experimental modal analysis of the scaled model of the investigated characteristics of scaled model using forced vibration tests. The laboratory model was a welded-steel space frame with six legs, braces with horizontal and diagonal members, twostory decks and eight skirt piles. The details of the model are as shown in Fig. 7. Due to available pipes and laboratory facilities, the geometric scale used was 1:15. The legs had a diameter of $48 \mathrm{~mm}$ and a wall thickness of $3 \mathrm{~mm}$. For considering joint cans in the jacket the thickness of legs was increased to $5 \mathrm{~mm}$. All bracing in the diagonal and in the horizontal plane was $34 \mathrm{~mm}$ in diameter. The deck was consisted of intersectional beams, and its weight was considered by welding a thick plate $(15 \mathrm{~mm})$. Eight skirt piles with $88.9 \mathrm{~mm}$ in diameter, was connected to the legs. Totally 4 sample of pipes was tested, one samples was tested for each size of used pipes. The modulus of elasticity of steel piles was determined $200 \mathrm{GPa}$ and a yield stress varied from 265 to 285 $\mathrm{MPa}$.

\subsubsection{Installation of the platform in homogeneous soil}

The foundation system in fixed offshore platform are piles with sufficient penetration in the soil to resist the lateral and vertical loads. The effect of soil-pile interaction in the response of the structure to the time-varying loads is the important issue. Therefore, for investigation of the dynamic behavior of the scaled platform in this study and taking into account the flexibility of base conditions, a square pit approximately $7 \mathrm{~m} \times 7 \mathrm{~m}$ in size was excavated in the yard of civil engineering faculty of $\mathrm{K}$. N. Toosi University of Technology. The pit was filled about $320 \mathrm{~m}^{3}$ of homogenous sand. The soil profile consisted of uniformly graded sand with an angle of internal friction, $\varphi$ of $38^{\circ}$ and undrained shear strength, $c_{\mathrm{u}}$ of $9.8 \mathrm{kN} / \mathrm{m}^{2}$.

The installation process of the scaled platform was conducted by driving eight piles from skirt piles. Piles had a diameter of $60.3 \mathrm{~mm}$, with total length of $6 \mathrm{~m}$ and $5 \mathrm{~m}$ of penetration in soil.

The connection between leg and pile consisted of flange plates, shear plates, skirt-pile sleeves, and grout connections. After the completion of the pile driving process, one was grouted in the gap between pile and leg. Fig. 8 shows the scaled model of the platform installed in the dense uniform sand. More detail on the experimental work is presented in Asgarian et al (2012).

The response of the scaled model platform in both directions (Rows A \& C and Rows 1 \& 2) subjected to forced vibration at the top level of the deck was measured in several stages. The first stage of the test was conducted by increasing the input frequency from 1 to $4 \mathrm{~Hz}$ with an increment of $0.2 \mathrm{~Hz}$. In this stage the approximate modal frequency values were evaluated. In the next stage of forced vibration test program the exact value of natural frequencies and corresponding mode shapes were evaluated. In these stages the frequency of excitation was increased around the preliminary resonant frequencies with an increment of $0.1 \mathrm{~Hz}$ and the response of the platform was measured by accelerometers.

The response of the structure to the excitation was derived from forced vibration tests. To identify modal characteristics of the scaled platform, the signal processing method was used based on the power spectral density function and cross spectral density. The dynamic theory, half-power bandwidth, was used for calculating the modal damping (De Sortis et al, 2005; Ivanović et al, 2000; Ventura et al, 2003).

By implementing the signal processing analysis for a scaled platform, four vibration modes were identified. The power spectral density (PSD) and cross spectral density (CSD) of the acceleration No. 1 and No. 2 are shown in the Fig. 9. Natural frequencies in the Rows A \& C and Rows $1 \& 2$ and 

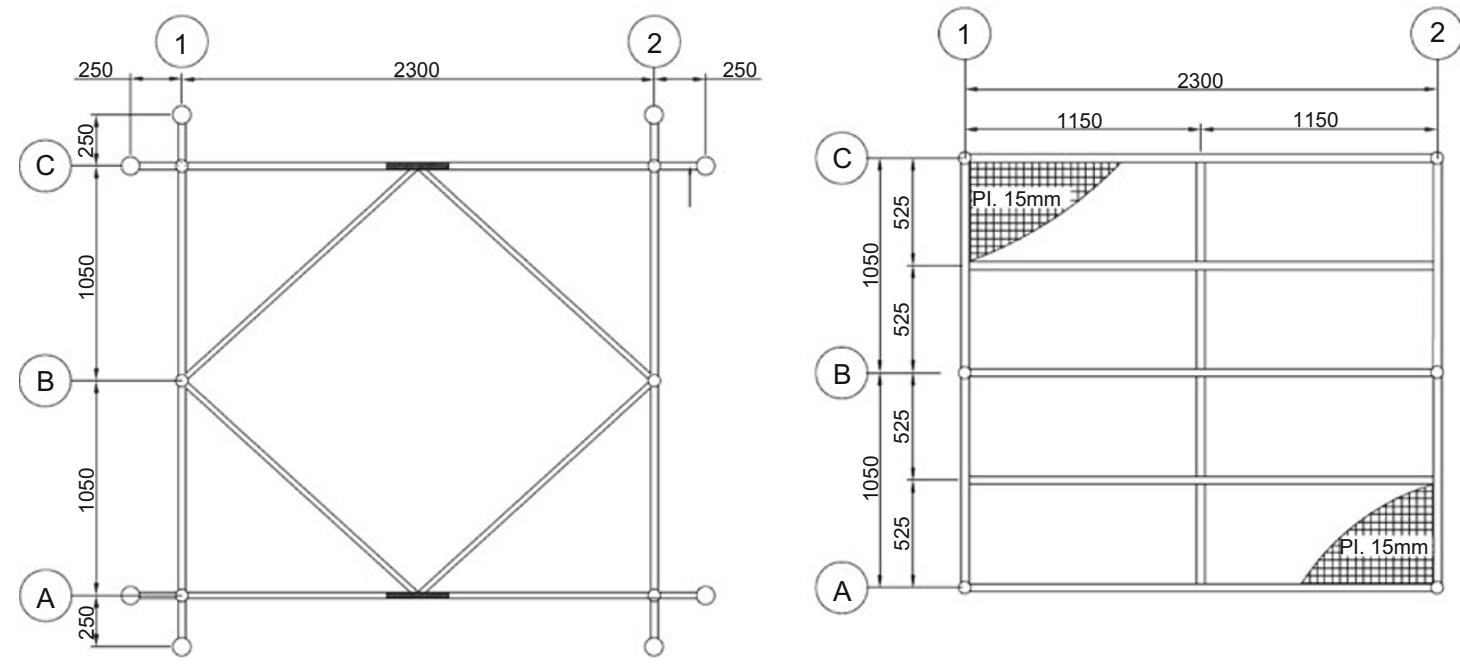

(2)

Jacket plan Deck plan
Sc: $1 / 100$
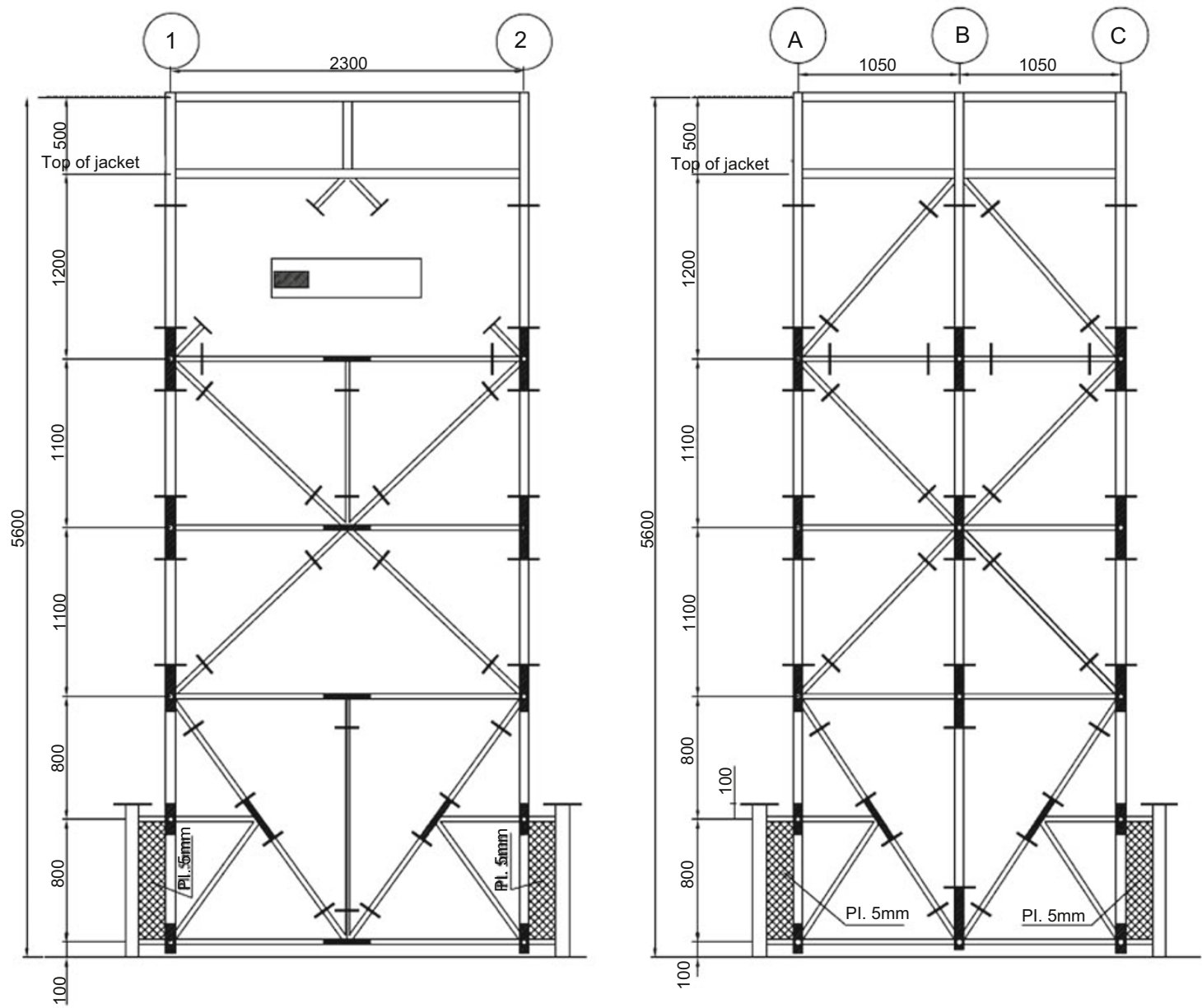

Rows A \& C

Rows 1 \& 2 Sc: $1 / 100$

Fig. 7 Plans and rows of the scaled model platform (All dimensions are in millimeters)

the corresponding damping ratio are presented in Table 5 . The first and second natural frequencies in Rows 1 \& 2 was $41 \%$ and $35 \%$ more than values in Rows A \& $\mathrm{C}$ respectively, but the damping ratios were approximately the same for both directions. Mode shapes of the platform in both directions are shown in Fig. 10. 


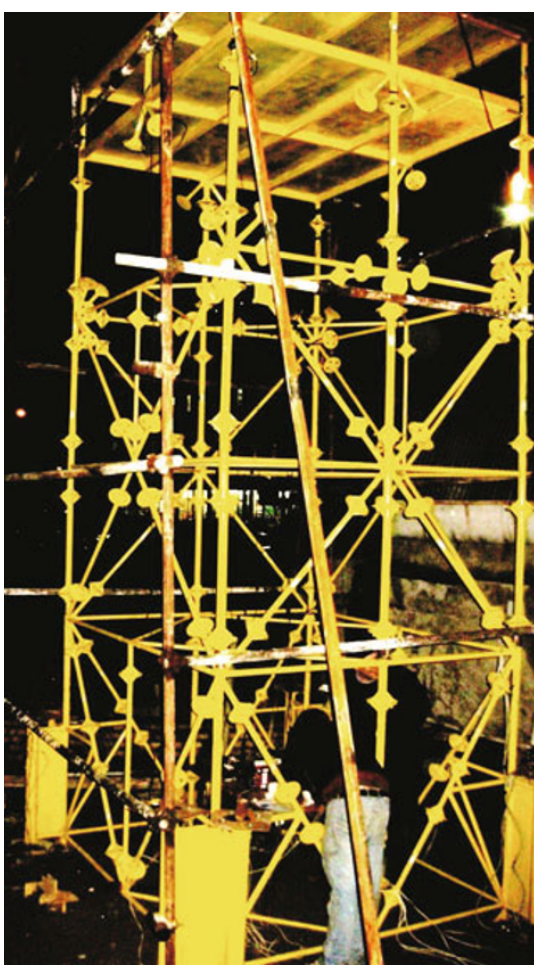

Fig. 8 Picture of the scaled model platform installed in the dense uniform sand

By comparing the natural frequency and the mode shape of this type of platform, different behavior is observed in each direction. In Rows A \& $\mathrm{C}$ the system is more flexible and vertical irregularity exists, but in Rows $1 \& 2$ the system is stiffer and more regular in the vertical direction. This behavior is also realized by comparing the history of displacement recorded at each row (in Fig. 11). The displacement of the top (elevation $+5.6 \mathrm{~m}$ ) of the scaled platform in Rows A \& $\mathrm{C}$ is much larger than those in Rows $1 \& 2$. The same results are observed for the bottom (elevation $+0.1 \mathrm{~m}$ ) of the platform.

Table 5 The natural frequency and the damping ratio

\begin{tabular}{ccccccc}
\hline & \multicolumn{2}{c}{ Natural frequency } & & \multicolumn{2}{c}{ Damping ratio } \\
\cline { 6 - 6 } \cline { 5 - 6 } & Model 1 & Model 2 & & Model 1 & Model 2 \\
\hline Rows A \& C & 2.754 & 11.016 & & 0.0132 & 0.00408 \\
Rows 1 \& 2 & 4.668 & 16.875 & & 0.0150 & 0.00406 \\
\hline
\end{tabular}

\section{Propose of offshore installed bracing system}

Probabilistic seismic assessment of the newly designed steel jacket offshore platform with the FOD installation system was revealed that the bracing configuration of the structure in Rows A \& C needs modification to improve the seismic performance of the structure. To do this, an offshoreinstalled bracing system compatible with the float over deck installation operation was proposed. In the proposed system, the horizontal and diagonal braces in the Rows A \& $\mathrm{C}$ at the top of the jacket can be assembled after the FOD installation operation. For this purpose, short stubs, welded at one side into the jacket leg with a flange plat at the other side for bolted connection, need to be provided during fabrication of the jacket. Proposed bracing elements can be easily installed after deck installation. The scheme of the proposed configuration is shown in the Fig. 12.

\subsection{Probabilistic seismic assessment of the proposed bracing system}

The vertical bracing system proposed in this paper was designed for the platform considering design requirements. Then, the modified platform was modeled by the similar assumptions which have been described in Section 2. The nonlinear time history analysis of the modified offshore platform was performed using the same sixteen ground motions (Table 2). IDA curves of the structure in Rows A \& C direction are shown in Fig. 13. Fig. 14 shows the summarized form of these IDA curves.

The probabilistic seismic assessment of this structure in Rows A \& $\mathrm{C}$ was also estimated. The fitted curve to median IDA curve in Fig. 14 (curve 50\% in the Rows A \& C) was obtained as follows (Fig. 15):

$$
\eta_{D}(x)=a x_{a}^{b}=0.051 x_{a}^{1.728}, r=0.983
$$

The limit state capacities, $C$, the fractional standard deviation of demand and capacity, $\beta_{\mathrm{RD}}$ and $\beta_{\mathrm{RD}}$ were estimated from the result of incremental dynamic analysis and are shown in Table 6. Fractional standard deviations of demand and capacity, $\beta_{\mathrm{RD}}$ and $\beta_{\mathrm{RD}}$, were calculated.

The mean annual frequency of exceedance from each limit state is shown in Table 7. Similar to the previous calculation, the spectral acceleration corresponding to given capacity, $S_{a}^{\eta_{c}}$, was found graphically. It can be seen that the proposed bracing configuration for the platform with the FOD system in Rows A \& C satisfies the recommended performance levels and the MAF of exceeding the limit states is larger than the specified value.

Table 6 Summarized capacities, randomness and uncertainty parameters at each limit-state of the modified Rows A \& C

\begin{tabular}{|c|c|c|c|c|c|c|c|c|c|c|c|c|c|}
\hline & \multicolumn{5}{|c|}{ Capacity parameters } & \multicolumn{4}{|c|}{ Randomness } & \multicolumn{4}{|c|}{ Uncertainty } \\
\hline & \multirow{2}{*}{ Percentile } & \multicolumn{2}{|c|}{$\theta_{\max }$} & \multicolumn{2}{|c|}{$S_{a}\left(T_{1}, 5 \%\right)$} & \multicolumn{2}{|c|}{$\beta_{\mathrm{RD}}$} & \multicolumn{2}{|c|}{$\beta_{\mathrm{RC}}$} & \multicolumn{2}{|c|}{$\beta_{\mathrm{UD}}$} & \multicolumn{2}{|c|}{$\beta_{\mathrm{UC}}$} \\
\hline & & IO & $\mathrm{CP}$ & IO & $\mathrm{CP}$ & IO & $\mathrm{CP}$ & IO & $\mathrm{CP}$ & IO & $\mathrm{CP}$ & IO & $\mathrm{CP}$ \\
\hline \multirow{3}{*}{$\begin{array}{l}\text { Rows } \\
\text { A \& C }\end{array}$} & 16 & 0.01 & 0.091 & 0.31 & 1.78 & \multirow{3}{*}{0.44} & \multirow{3}{*}{0.50} & \multirow{3}{*}{0.48} & \multirow{3}{*}{0.36} & \multirow{3}{*}{0.11} & \multirow{3}{*}{0.125} & \multirow{3}{*}{0.12} & \multirow{3}{*}{0.09} \\
\hline & 50 & 0.01 & 0.1 & 0.40 & 2.40 & & & & & & & & \\
\hline & 84 & 0.01 & 0.1 & 0.79 & 3.06 & & & & & & & & \\
\hline
\end{tabular}



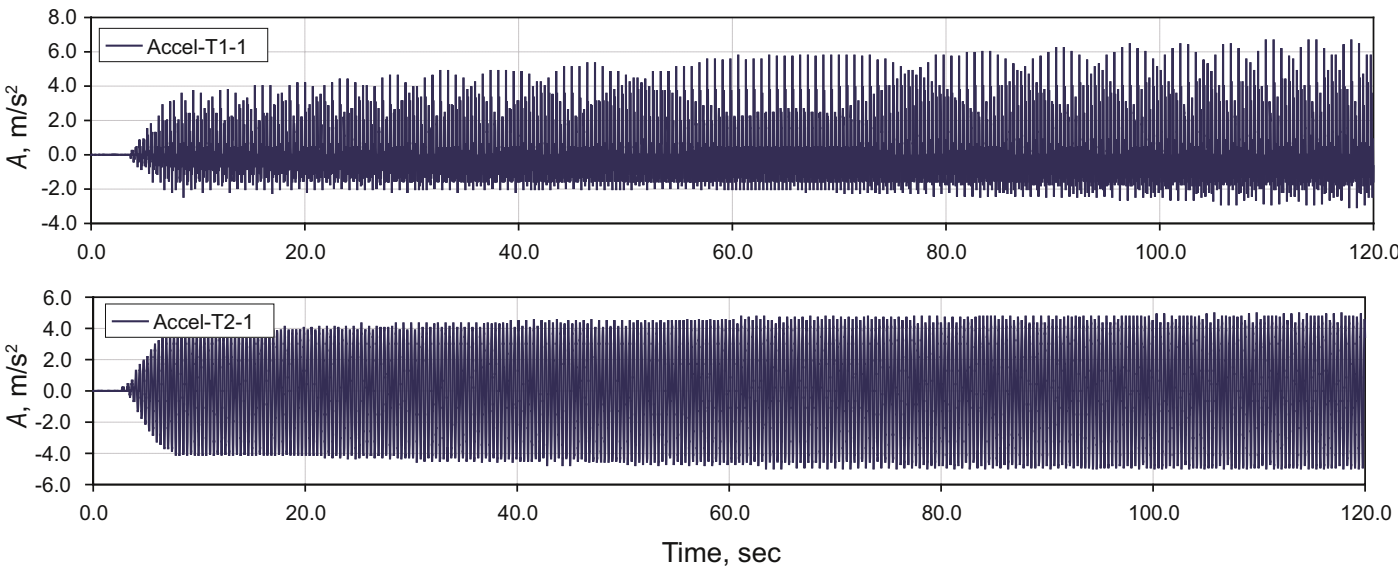

(a)
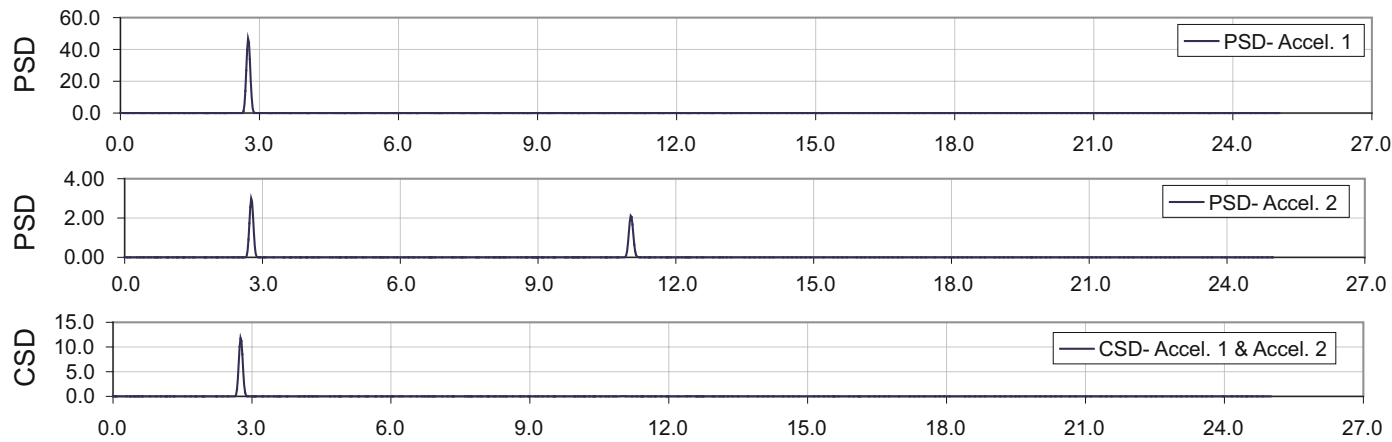

(b)

Fig. 9 (a) Recorded acceleration in Rows A \& C for acceleration No. 1 \& 2; (b) respectively, power spectral density (PSD) of acceleration No. $1 \&$ No. 2 , cross spectral density (CSD) between acceleration No. $1 \&$ No. 2

Mode shape No. 1

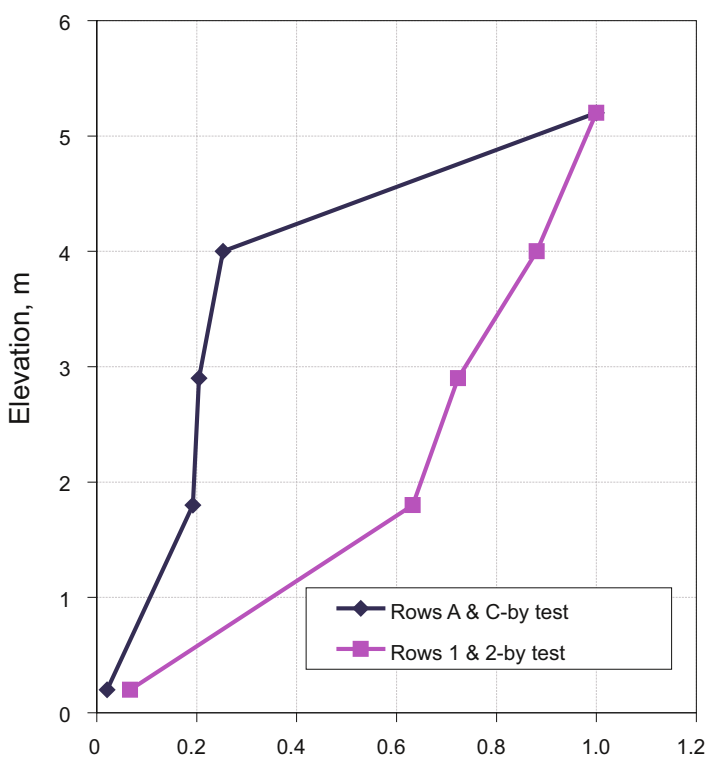

Mode shape No. 2

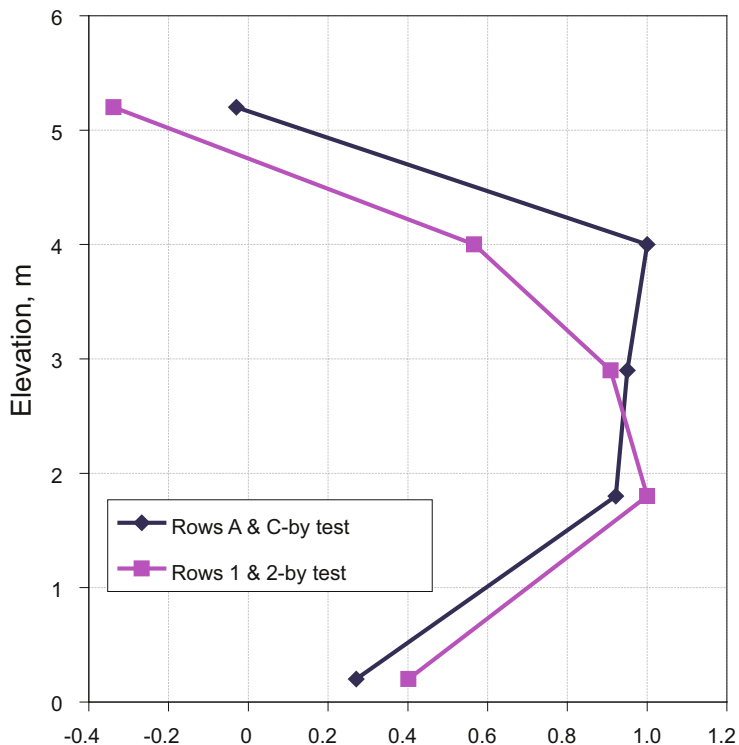

Fig. 10 Mode shapes of the scaled platform in Rows A \& C and Rows $1 \& 2$

Table 7 MAFs of exceedance and corresponding return periods for modified Rows A \& C

\begin{tabular}{ccc}
\hline & \multicolumn{2}{c}{ Rows A \& C } \\
\cline { 2 - 3 } & IO & CP \\
\hline$H_{\mathrm{LS}}$ (MAF of exceedance) & 0.00522 & 0.000045 \\
Return period, Years & 191 & 22261 \\
\hline
\end{tabular}

3.2 Identification of the dynamic characteristics of the scaled platform with the new bracing system

Efficiency of the proposed bracing system was investigated experimentally by adding vertical bracing in the top bay of the jacket in Rows A \& C to the prototype model. Experimental modal analysis of the modified platform was also carried out using the same forced vibration test. 

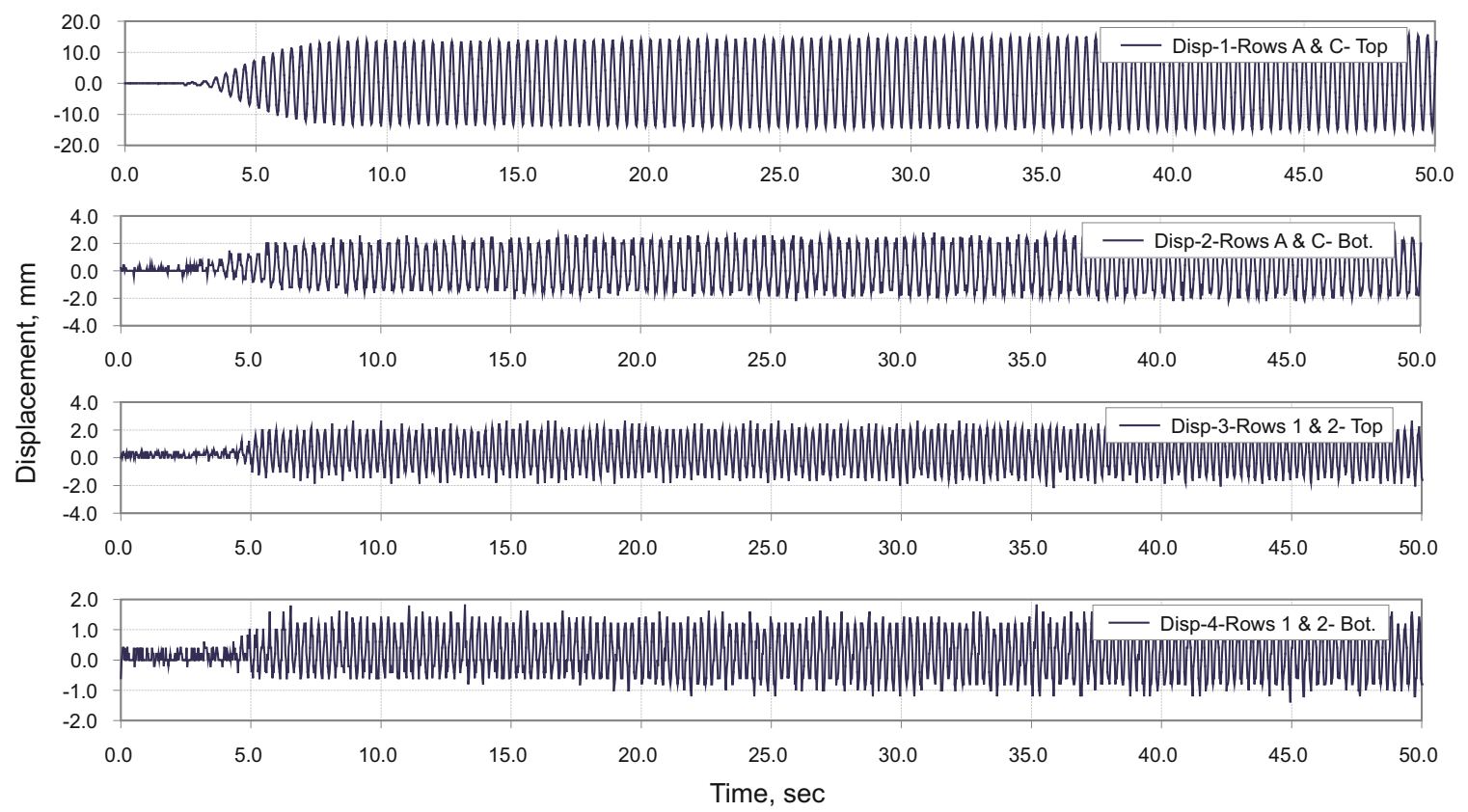

Fig. 11 Displacement of the top and bottom of the scaled platform at the first-order approximate resonant frequency in Rows A \& C and Rows 1 \& 2

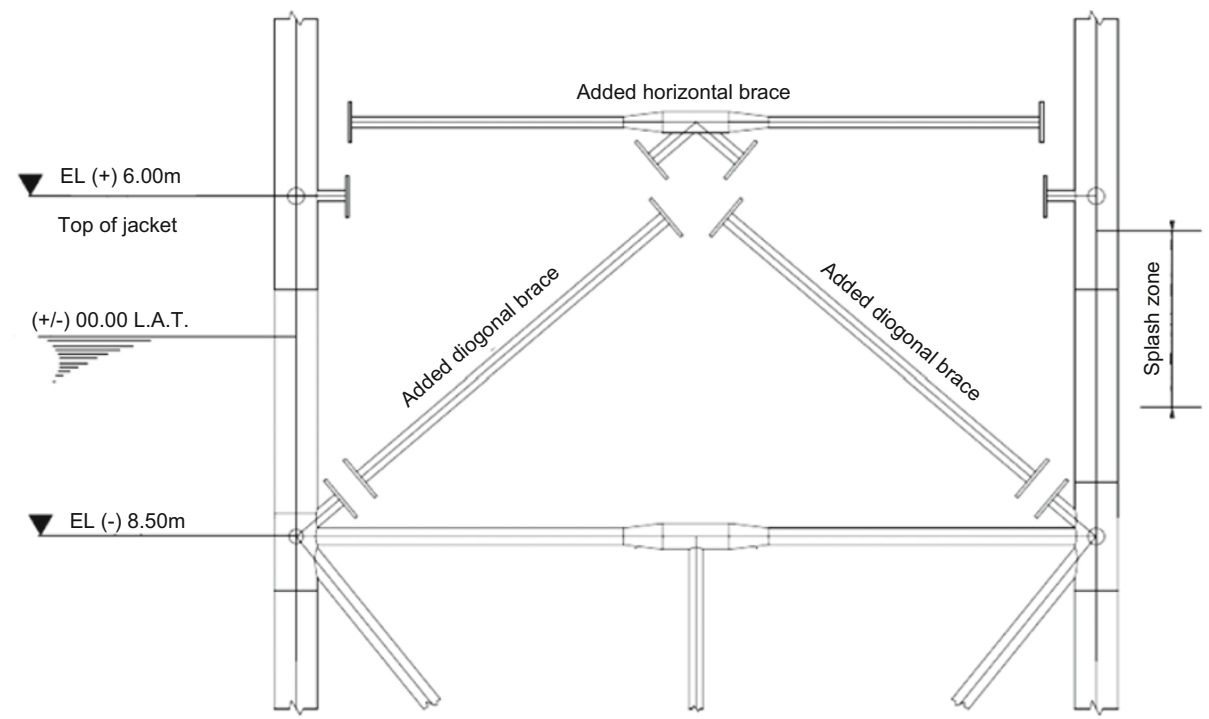

Fig. 12 Scheme of modified bracing configuration of the steel jacket platforms with FOD installation system in Rows A \& C

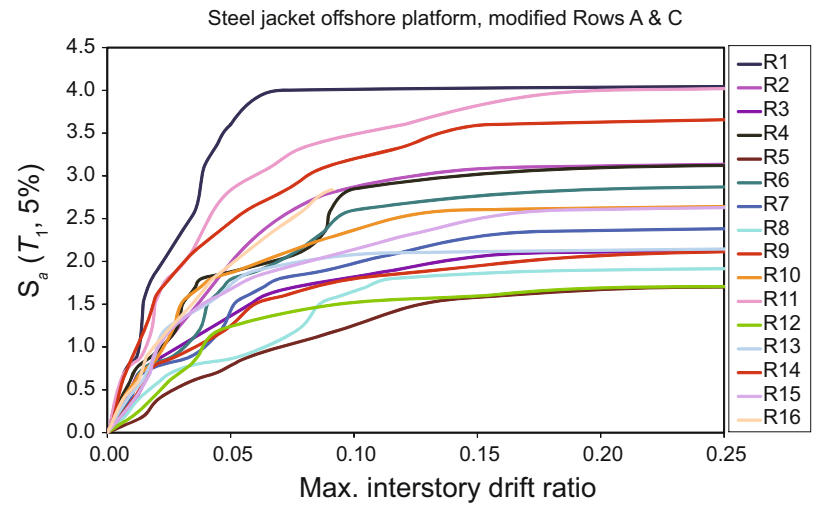

Fig. 13 IDA curves (for $T_{1}=2.63 \mathrm{sec}$ ), steel jacket offshore platform in the modified Rows A \& C, with maximum interstory drift ratio

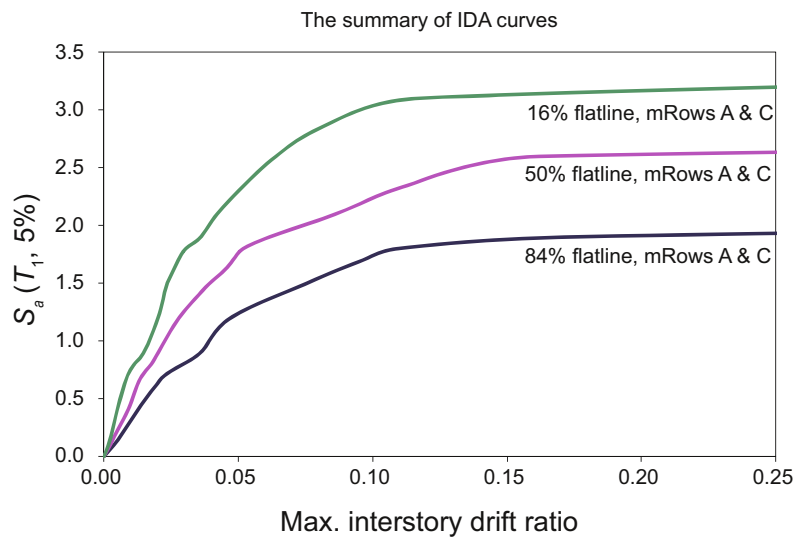

Fig. 14 The summary of IDA curve in the modified Rows A \& C 


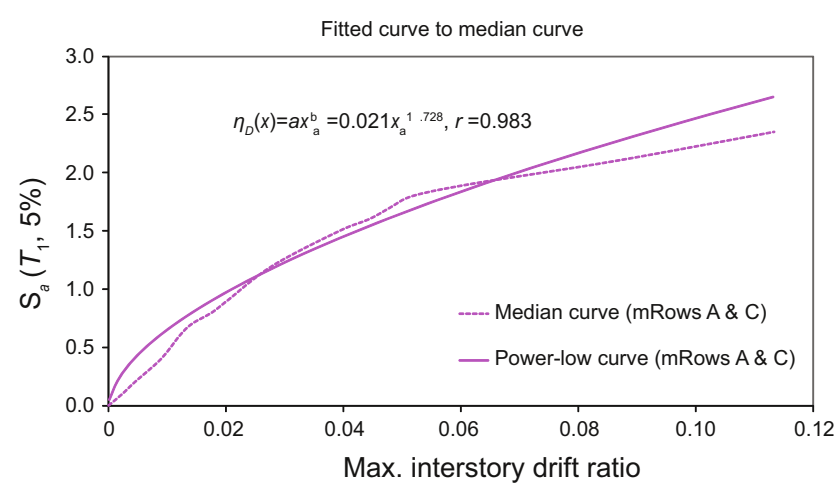

Fig. 15 Power-law relation fitted to median curve of the modified Rows A \& C

Table 8 shows the natural frequency of the platform in new conditions. It was observed from changes in natural frequency that the new bracing system worked very well and jackets in the new configuration were stiffer compared to the original design. Fig. 16 shows the mode shape of the platform in new conditions. Fig. 17 shows the displacement-time histories for the top and bottom elevation of platform. By comparison of displacement with those before adding the proposed bracing, it can be seen that the proposed bracing system decreased the displacement of the system subjected to lateral loads.

Table 8 The natural frequency and the damping ratio of the scaled platform at Rows A \& C with modified braces

\begin{tabular}{cccccc}
\hline & \multicolumn{2}{c}{ Natural frequency } & & \multicolumn{2}{c}{ Damping ratio } \\
\cline { 2 - 3 } \cline { 5 - 6 } & Mode 1 & Mode 2 & & Mode 1 & Mode 2 \\
\hline $\begin{array}{c}\text { Modified } \\
\text { Rows A \& C }\end{array}$ & 4.082 & 14.121 & & 0.01203 & 0.00382 \\
\hline
\end{tabular}
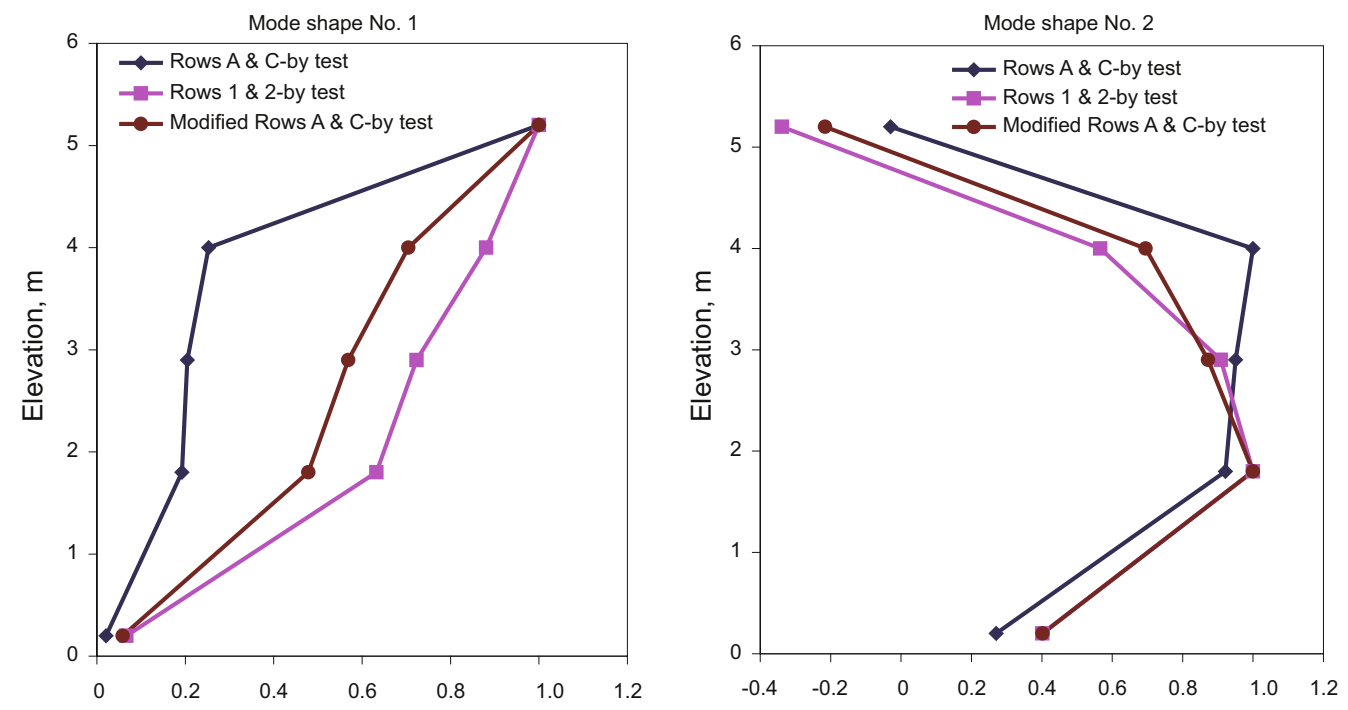

Fig. 16 Mode shapes of the scaled platform after modified braces in Rows A \& C

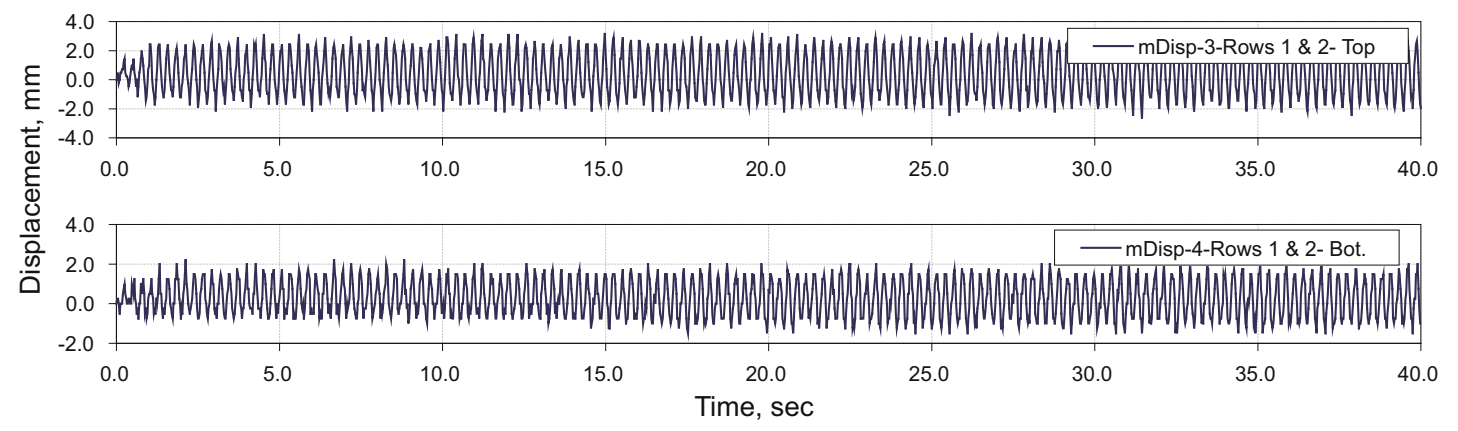

Fig. 17 Displacement of the top and bottom of the scaled platform at the first-order approximate resonant frequency in modified Rows A \& C

\section{Conclusions}

In this paper probabilistic performance was applied for the seismic performance assessment of a newly designed jacket type offshore platform with the float over deck installation system. It was observed from analysis results that due to lack of vertical bracing in the top bay of the jacket in the float over direction, design requirements were not satisfied. Probabilistic assessment indicated that MAF and the confidence level of these types of platforms were not satisfied for both immediate occupancy and collapse prevention performance levels in the direction of float over deck installation. Also from measured dynamic characteristics of the scaled model, it was observed that the dynamic characteristics in the float over direction 
were totally different from those in the other direction.

An offshore installed bracing system for top bay of the jacket was proposed for upgrading seismic performance in the float over direction. Probabilistic seismic assessment of platforms with the modified bracing configuration was also performed. The result showed that the proposed bracing configuration upgraded seismic performance of the platform in the FOD direction. Changes in dynamic characteristics of the scaled model test indicated that the proposed bracing system worked well.

\section{Acknowledgements}

The research was sponsored by POGC (Pars Oil and Gas Company, No. 132 "Investigation of Structural Health Monitoring of Steel Jacket Offshore Platforms"). The financial support of POGC is gratefully acknowledged.

\section{References}

American Petroleum Institute. Recommended practice for planning, designing and constructing fixed offshore platforms. API Recommended Practice 2A (RP-2A). $21^{\text {st }}$ edition, American Petroleum Institute, Washington, D.C., 2000

Asgarian B, Rahman Shokrgozar H, Shahcheraghi D, et al. Effect of soil pile structure interaction on dynamic characteristics of jacket type offshore platforms. Coupled Systems Mechanics. 2012. 1(4): 381395

Bardet J P and Tobita T. NERA. A computer program for nonlinear earthquake site response analysis of layered soil deposits. Technical report, Department of Civil Engineering, University of Southern California, 2001

Berger E, Mahin S A and Pyke R. Simplified method for evaluating soilpile-structure interaction effects. Proceedings of the 9th offshore Technology Conference, 2-5 May 1977, Huston, Texas (paper SPE 2954)

Boulanger R W, Curras C J, Kutter B L, et al. Seismic soil pile structure interaction experiments and analysis. Journal of Geotechnical and Geo environmental Engineering. 1999. 125(9): 750-759

Causevic M S. Mathematical modeling and full-scale forced vibration testing of a reinforced concrete structure. Engineering Structures. 1987. 9(1): 2-8

De Sortis A, Antonacci E and Vestroni F. Dynamic identification of a masonry building using forced vibration tests. Engineering Structures. 2005. 27(2): 155-165

FEMA. Recommended seismic design criteria for new steel momentframe buildings, Report No. FEMA-350, SAC Joint Venture,
Federal Emergency Management Agency, Washington, D.C., 2000a

FEMA. Recommended seismic evaluation and upgrade criteria for existing welded steel moment-frame buildings. Report No. FEMA351, SAC Joint Venture, Federal Emergency Management Agency, Washington, D.C., 2000b

FEMA. Recommended post-earthquake evaluation and repair criteria for welded steel moment-frame buildings. Report No. FEMA352, SAC Joint Venture, Federal Emergency Management Agency, Washington, D.C., 2000c

Ivanović S S, Trifunac M D, Novikova E I, et al. Ambient vibration tests of a seven-story reinforced concrete building in Van Nuys, California, damaged by the 1994 Northridge earthquake. Soil Dynamics and Earthquake Engineering. 2000. 19(6): 391-411

Iwan W D. On a class of models for the yielding behavior of continuous and composite systems. Journal of Applied Mechanics. 1976. 34: $612-617$

Jalayer F and Cornell C A. A technical framework for probability-based demand and capacity factor design (DCFD) seismic formats. Report No. 08 to the PEER Center, Department of Civil and Environmental Engineering, Stanford University, Stanford, CA 2003

Jalayer $\mathrm{F}$ and Cornell $\mathrm{C} \mathrm{A}$. Alternative nonlinear demand estimation methods for probability-based seismic assessments. Earthquake Engineering and Structural Dynamics. 2009. 38(8): 951-972

Kimiaei M, Shayanfar M A, El Naggar M H, et al. Nonlinear response analysis of offshore piles under seismic loads. 13th World Conference on Earthquake Engineering, Vancouver, B.C., Canada, 2004. Paper No. 3056

Mazzoni S, McKenna F, Scott M H, et al. OpenSees Command Language Manual. 2006

Mróz Z. On the description of anisotropic work hardening. Journal of Mechanics and Physics of Solids. 1967. 15(3): 163-175

O'Neill L A, Fakas E, Ronalds B F, et al. History trends and evolution of float over deck installation in open waters. SPE Annual Technical Conference and Exhibition, 1-4 October 2000, Dallas, Texas (paper SPE 63037)

Salawu O and Williams C. Review of full-scale dynamic testing of bridge structures. Engineering Structures. 1995. 17(2): 113-121

Seed H B and Idriss I M. Soil moduli and damping factors for dynamic response analysis. Earthquake Engineering Res. Ctr., University of California, Berkeley, Calif. 1970, Report No. UCB/EERC-70/10

Shome N and Cornell C A. Probabilistic seismic demand analysis of nonlinear structures. Report No. RMS-35, RMS Program, Stanford University, Stanford. Structural Dynamics, 1999. 31, 491-514

Ventura C E, Liam Finn W D, Lord J F, et al. Dynamic characteristics of a base isolated building from ambient vibration measurements and low level earthquake shaking. Soil Dynamics and Earthquake Engineering. 2003. 23(4): 313-322

(Edited by Sun Yanhua) 